\title{
Assimetria nas relações internacionais, propriedade industrial e medicamentos anti-aids
}

\author{
Asymmetry in international relations, \\ industrial property rights and anti-HIV medication
}

M aria H elena Costa-Couto ${ }^{1}$

Álvaro César $\mathrm{N}$ ascimento ${ }^{2}$

${ }^{1}$ Departamento de Planejamento e Administração em Saúde, Instituto deM edicina Social UERJ. RuaSão Francisco Xavier 524/Pavilhão João Lyra Filho/7009 Bl. E, M aracanã. 20550-900 Rio deJaneiro RJ. costacoutomh@gmail.com ${ }^{2}$ Escola Nacional de Saúde Pública, Fundação Oswaldo Cruz.
Abstract This paper analyzes the asymmetry in the international relations as refers to the recognition of industrial property rights in the pharmaceutical industry. It focuses on the impact of such relations upon the access to ARV medication, an issue of worldwide interest due to its connection with the development of the nations. Clashing interests and the position taken by some countries in their patent laws point to a scenario less favorable for the access of peripheral countries to anti-HIV/AIDS medication. On the other hand, it seems that the success of the Brazilian STD/AIDS program in negotiating ARV prices will open new possibilities. The solution may be the internal strengthening of the $\mathrm{N}$ ational States and the active role played by the Agencies of the United $\mathrm{N}$ ations System in defense of the collective human interests.

Key words AIDS, Asymmetry, D evelopment, Medication, Industrial property rights, International relations
Resumo Esteartigo analisa a assimetria nasrelações internacionais entre países no que diz respeito ao reconhecimento da propriedade industrial no setor específico da indústria farmacêutica. 0 foco é o impacto destas relações no acesso a medicamentos anti-retrovirais (ARV), questão de interesse mundial em face da sua relação com 0 desenvolvimento das nações. A disputa de interesses no campo eo posicionamento deal guns paísesfrente às leis patentárias, ao longo do tempo, apontam um cenário pouco favorável para acesso aos medicamentos anti-aids pelos países que não pertencem ao núcleo do sistema mundial. 0 sucesso do programa brasileiro de Doenças Sexualmente Transmissíveis (DSTs) e Aids nas negociações dos preços dos ARV, ao contrário, aponta para novas possibilidades de enfrentamento desta realidade. A saída parece ser o fortalecimento interno dos Estados Nacionais e um papel ativo das Agências do Sistema das $\mathrm{N}$ ações $\mathrm{U}$ nidasna defesa dosinteresses humanos coletivos.

Palavras-chave Aids, Assimetria, Desenvolvimento, M edicamentos, Propriedade industrial, Relações internacionais 
Introdução

Este texto analisa, de forma resumida, a assime tria hoje existentenas relações internacionais entre países, no quediz respeito ao reconhecimento da propriedade industrial de inovações relativas a produtos e processos tecnológicos no setor específico da indústria farmacêutica. 0 seu foco está no impacto destas relações no acesso a me dicamentos anti-aids e nas conseqüências sociais eeconômicas dele resultantes nos países que não pertencem ao núcleo central do sistema mundial. Procura-se demonstrar aqui a proximidade de iniciativas das áreas de saúde coletiva e relações internacionais que trazem impacto direto à saúde global.

0 acesso aos medicamentos anti-aids é um problema de interesse mundial, em face do entrave que representa ao desenvolvimento das nações. Por outro lado, o programa brasileiro desafia as regras hoje estabelecidas pelo modelo de relações inter estatais.

A partir da identificação dos múltiplos interesses, atores e projetos conflitantes em face da assimetria de poder entre os países, suas indústrias e mercados, prioriza-se a compreensão das implicações do não-acesso aos medicamentos por países mais pobres. A bioética eo campo dos direitoshumanos poderiam auxiliar na argumentação sobre a legitimidade do acesso, livre desenvolvimento e comercialização de produtos farmacêuticos para o cuidado de pessoas doentes e sob risco de vida. M as acredita-se que o projeto brasileiro não encontrou aí sua força motriz.

0 entendimento parcial de como e porquê 0 Brasil consegue avançar nas negociações neste setor pode se aproximar do debate estabelecido no campo das relações internacionais, área de investigação intensificada, na década de 1970, para entender e explicar a suposta crise da hegemonia americana. Este campo incorpora diferentes linhas de pesquisa sobre a teoria da hegemonia mundial, seus fundamentos, pré-condições eresultados. Dentre os vários autores envolvidos no estudo das relações internacionais e da hegemonia se destacam: Robert Gilpin eCharles Kindleberger (neo-realistas); Susan Strange e Andrew Walter (estruturalistas); Joseph Nye e Robert Keohane (liberais) e Giovanni Arrigui e Robert Cox (neomarxistas). Em comum, estes estudos traduzem o termo hegemonia como dominação, mas diferem muito entre si ${ }^{1,2}$.

Analisando a produção no campo das relações internacionais sobre hegemonia, Fiori ${ }^{2}$ destaca, dentre outros autores, a produção do neo- marxista Robert Cox, que aponta a necessidade de se olhar para o movimento mundial na sua totalidade e tomar cuidado para não "reificar" um sistema mundial, não subestimar o poder do Estado, e dar a "devida atenção às forças e processos sociais", mais especificamente, como se relacionam com o desenvolvimento dos estados e da ordem mundial.

Ainda segundo Fiori, Cox ressalta que a discussão da hegemonia internacional não pode se resumir à universalização dos interesses nacionais da potência hegemônica, pois o interessedos estadosnacionaisé fruto das "contradições econflitos entre classes, frações de classes edentro das burocracias estatais". Estes interesses estão presentes nos "elementos internos" dos Estados, nas suas "estruturas históricas" que são a sua "capacidade material, instituições eidéi as" eestas sempre estão comprometidas com a "organização da produção e das forças sociais", com as formas dos Estados e com as configurações do poder mundial.

Talvez seja esta uma das razões que fazem Fiori afirmar não existir evidência - como gostariam de crer alguns - de que a globalização esteja "reduzindo o poder das grandes potências, diminuindo o papel dos estados nacionais" ou promovendo o desenvolvimento global em direção à convergência de interesses, de modo a tornar 0 mundo mais "homogeneizado e inclusivo". Ao contrário, a realidade mostra crescente acirramento das desigualdades entre todos os países (desenvolvidos ou periféricos) e entre as classes sociais. A "assimetria de poder e a dominação estão na origem do projeto globalizante" e é o que explica o seu êxito e a sua força².

A pesar dessa tendência global ser observada também na questão do acesso aos medicamentos, não deve ser encarada com absoluto pessimismo, haja vista 0 avanço permanente do Brasil, país em desenvolvimento e que não pertence ao núcleo central do sistema mundial, nas negociações neste campo.

\section{O problema}

Em relatório mundial, tornado público em maio de2004, a Organização M undial da Saúde (OM S) alerta que o mundo está despreparado para lidar com os impactos sociais e econômicos da epidemia de aids. Para a OM S, caso as nações não se unam para combater a doença, a aids vai destruir a esperança de vida de outras dezenas de milhões de pessoas, principal mente as que vivem 
em países pobres. $\mathrm{Na}$ África, por exemplo, a Organização estima que um em cada doze habitantes porte o vírus. A doença já éa principal causa de morte entre pessoas dos 15 aos 59 anos naquele continente eestáinviabilizando os esforços para se atingir as metas do milênio, como a erradicação total, até 2015, da pobreza extrema, da fome, a redução da mortalidade infantil e materna e a expansão da educação primária. 0 relatório da O M S revela, ainda, que existem de trintae quatro milhões a quarenta e seis milhões de pessoas infectadas com 0 vírus da aids em todo 0 mundo e que a cada ano outras cinco milhões tornam-sesoropositivas. E mais: das seis milhões de pessoas que já necessitam de tratamento, ape nas 400 mil tiveram acesso a ele em $2003^{3}$.

Nosso ponto de partida para analisar o impacto da assi metria das relações internacionais e da aplicação dos tratados sobre propriedade industrial no acesso a medicamentos é o pedido formal - apresentado pelo governo dos Estados Unidos da América em 2001, no âmbito da Organização M undial do Comércio (OMC) -, para que fosse instalado um tribunal sobre a atual Lei de Patentes do Brasil. A queixa do governo americano se concentrava no fato do sistema brasileiro de garantia de patentes assegurar a possibilidade de se utilizar "Iicenças compulsórias", ou seja, o direito do governo brasileiro não reconhecer as patentes em algumas circunstâncias, com o objetivo de atender a interesses nacionais.

A motivação que sustenta a queixa americana está centrada nos interesses de sua indústria farmacêutica, detentora da maioria das patentes já registradas no Instituto Nacional de Propriedade Industrial (INPI) brasileiro. Para os interesses norte-americanos, seria um risco se o Brasil viesse a utilizar a "licença compulsória" como instrumento para baixar os altos preços dos medicamentos para aids, hoje oferecidos aos cidadãos pelo Programa Brasileiro deDST eAids (PN/DST/ AIDS) por meio do SistemaÚ nico deSaúde(SUS).

Há, ainda, outra questão associada a esta. Se, de fato, o Brasil usar a "licença compulsória" e produzir os medicamentos anti-retrovirais (ARV), o país pode, em tese, no futuro, oferecer estes produtos a preços mais acessíveis aos demais países em desenvolvimento, que hoje não conseguem assegurar 0 acesso a estas drogas às suas populações devido ao alto preço cobrado pelas multinacionais farmacêuticas. 0 conflito de interesses pode ser demonstrado pelos preços de medicamentos para aids em países que respeitam patentes, que giram em torno de dez mil dólares por paciente/ano. Os mesmos medica- mentos em países que produzem suas próprias versões destas drogas chegam, no máximo, a trezentos dólares por paciente/ano ${ }^{4}$.

Vale frisar quea Lei de Patentes brasileira, de 1996, exige que o detentor da patente produza o medicamento no país, o que não éfeito até hoje no caso dos medicamentos ARV. Caso isso não aconteça, o governo pode emitir a "licença compulsória" para outro produtor, a menos que 0 detentor da patente possa provar que a produção local não é viável. Detentor de uma rede de dezoito laboratórios públicos produtores de medicamentos, o Brasil já produzia, antes da Lei de Patentes, medicamentos anti-aids a preços muito inferiores aos praticados pelas multinacionais farmacêuticas.

Em 22 de maio de 2004, o Brasil foi um dos propositores da emenda, aprovada na Assembléia Mundial deSaúde, que determinou aos Estados membros da OM S a incorporação, nos acordos bilaterais de comércio, da flexibilização do Trade-Related Aspects of Intellectual Property Rights (TRIPS - sigla inglesa para designar 0 acordo criado no âmbito da OMC sobre aspectos dos direitos de propriedadeintelectual relacionados ao comércio, que assegura o direito às suas patentes) ${ }^{6}$. Isto significa que questões como a produção local de medicamentos, a importação e a exportação de genéricos, a quebra de patentes em caso de emergência nacional, o abuso de preços ou a formação de cartel devem fazer parte dos acordos bilaterais sobre comércio que estão sendo estabelecidos. A incorporação da "flexibilização do TRIPS" vinha se tornando praticamente inviável diante das pressões dos países mais ricos sobre os mais pobres, que sem possibilidade denegociação, estavam direta ou indiretamente forçados a abrir mão dos seus direitos da chamada "licença compulsória".

Para se medir a gravidade da questão relativa ao acesso aos medicamentos ARV, o abuso de preços faz com que, segundo a OMS, apenas $10 \%$ das pessoas que na África e na Ásia necessitam de medicamentos anti-aids tenham acesso a estas drogas ${ }^{3}$. Este dado é confirmado por outros estudos, que afirmam que as populações dos países mais ricos têm mais acesso aos diferentes medicamentos existentes, sejam estes essenciais ou não ${ }^{5}$.

\section{História e contexto}

As patentes são criadas, ainda no século XIX, como instrumento de desenvolvimento tecnológico e industrial dos países signatários de trata- 
dos internacionais. N este momento, elas visam beneficiar tanto o proprietário da descoberta como as sociedades que desejavam utilizá-la. Em troca do pagamento de direitos de propriedade para uso de uma invenção, cada Estado passava a ter o direito de exigir a descrição completa do invento (de forma a acumular conhecimento naquele campo) e sua produção local (para fortalecer sua base industrial).

Em 1883, o Brasil é um dos onze signatários originais da Convenção deParis, que regulamenta pela primeira vez o tema. Em 1886, o Brasil também é co-autor da Convenção de Berna sobre propriedade intelectual, direito autoral e copyright. Ao longo de quase um século, o Brasil respeita a legislação internacional sobre patentes, apesar de nunca ser considerado país prioritário para seu depósito, ficando privado da descrição de inventos e da produção local de produtos. Só quando estas patentes caem em domínio público em todo o mundo é que o Brasil e outros países passam a utilizar os inventos, sem qualquer acusação de "pirataria".

No fim do século XIX, os Estados Unidos decidem reconhecer apenas as patentes deseus próprios cidadãos e reconhecem patentes de estrangeiros, desde que residentes há mais de dois anos em seu território. Em 1883, os Estados Unidos se negam a assinar a Conven ção de Paris, por considerá-la "restritiva a seu desenvolvimento" e, em 1886, pelo mesmo motivo, não assinam a Convenção de Berna. Assim, de 1891 a 1988, a legislação americana reconhece apenas o copyright para obras manufaturadas em território americano.

Durante trinta anos (de 1919 a 1949), a Inglaterra abandona o Sistema Internacional de Patentes, só voltando a reconhecêlo após considerar que sua indústria estava pronta para competir internacionalmente. Já a França, só em 1959, após mais de meio século da Convenção de Paris de 1883, passa a reconhecer as patentes farmacêuticas, desde que em regime especial, o que lhe dá a possibilidade de suspendêlas dependendo da quantidade, qualidade e dos preços praticados pelos detentores de seus direitos.

A partir dos anos setenta, os conceitos que regem o reconhecimento das patentes (acordos entre países que visam à garantia da divulgação da informação tecnológica, à difusão da indústria e ao desenvolvimento das nações signatárias) foram sendo paulatinamente abandonados em prol de uma nova concepção, voltada para assegurar maior controle de mercados, garantia de segredo das invenções e a remuneração da empresa proprietária da inovação.
A transferência da tecnologia em troca do respeito à invenção e a remuneração do inventor por determinado período de tempo é substituída pela pura e simples licença de uso do produto, sem que o país recebedor do invento tenha qualquer acesso a novos conhecimentos.

Vários países de desenvolvimento tecnológico mais incipiente, que ainda planejam o fortalecimento de sua indústria local, resistem à mudança do conceito e da lógica do reconhecimento das patentes através dos fóruns internacionais (basicamente ONU, OM C e OMS). Frente a esta "resistência", o sistema mundial e seus aliados no interior de cada país (a mídia entre eles) patrocinam uma avassaladora campanha mundial "denunciando a pirataria", que estaria sendo praticada pelos países que produzem versões de suas invenções. Estas "denúncias" são feitas como se os países centrais do sistema mundial não tivessem, por mais de um século, usufruído do direito de produzir suas versões, a título de "assegurar o desenvolvimento tecnológico" de suas nações.

A partir dos anos setenta, os países hegemônicos abrem negociações sobre esta nova lógica de reconhecimento da propriedade industrial na OM C. Assim, o Japão só reconhece patentes de fármacos após se transformar no segundo produtor mundial (1976), obtendo em troca livre acesso de seus produtos à Europa e Estados Unidos. A Suíça (terceiro produtor mundial de fármacos), só reconhece patentes em 1978, junto com a Itália. A Áustria (1987) ea Espanha (1986) o fazem para, em troca, serem admitidas na ComunidadeEconômica Européia, mas exigem prazo até 1992 para terem tempo para investir eabsorver tecnologia, diminuindo sua dependência ${ }^{6}$.

Em 1996, o Governo Federal utiliza sua maioria parlamentar e aprova uma nova Lei de Patentes para o Brasil, sob protesto de parte da comunidade científica e de dirigentes das instituições ligadas à ciência e tecnologia. Esses segmentos exigiam mais tempo para o debate e maior proteção aosinteresses nacionais, a exemplo de outros países.

Aids e medicamentos: problema de saúde de natureza global

Dos anos noventa aos dias atuais, um acelerado processo de concentração de capital etecnologia faz com que apenas nove empresas multinacionais controlem $80 \%$ do mercado mundial deprodutos farmacêuticos. São elas: Pfizer, Abott, Glaxo Smith Kline, Aventis, Astra Zeneca, Nycomed 
Amerssham, Novartis, Hoescht M arion Roussel ea Janssen Cilag.

A enorme concentração de tecnologia e capital no setor não leva, apenas, à criação de um oligopólio internacional. Produz, também, um aumento da rentabilidade média destas nove gigantes da indústria farmacêutica, queno ano 2000 chega a 45,3\%. Para se ter uma idéia da magnitude deste número, no mesmo ano, a rentabilidade média mundial dos bancos é de $16,7 \%$; da indústria química, 15,9\%; da indústria automobilística, $15,6 \%$ e das empresas de telecomunicações, $10,9 \%$.

A elevação dos preços de medicamentos em termos mundiais impacta diretamente os sistemas de saúde e a saúde dos povos. Isso ocorre com mais intensidade nos países que não detêm tecnologia para produzi-los e agora estão impedidos por suas próprias leis de patentes de manufaturar versões nacionais destas drogas.

Segundo a Organização Mundial de Saúde (OMS), desde o surgimento da epidemia de aids, no final da década de 1970, mais devintemilhões de pessoas morreram da doença e quatro miIhões de crianças foram infectadas. Desde meados da década de 1990, a epidemia avança velozmente nos continentes asiático e africano. Hoje, 2/3 da população afetada vive na África e 1/5 na Ásia. Só em 2003, três milhões de pessoas morrem em conseqüência das complicações de saúde por causa da síndrome. Das cerca de quarenta milhões de pessoas soropositivas estimadas, a maior parte se encontra no intervalo etário economicamenteprodutivo, compreendido entreos 25 e os 49 anos $^{3}$.

Se nos anos oitenta a epidemia é entendida e enfrentada como um problema de saúde pública, na década seguinte sua proliferação e recrudescimento - associado ao empobrecimento das nações - a torna um dos problemas centrais para a políticainternacional dedesenvolvimento. N este novo cenário, a aids se constitui como questão central para o desenvolvimento socioeconômico das nações, pois quanto maior sua incidência e/ ou prevalência, mais elevado éo índice deempobrecimento geral, menor o poder de consumo, maior o absenteísmo ao trabalho, maiores os gastos com o financiamento ea provisão pública e/ou privada dos serviços previdenciários, securitários, de saúde, entre outros ${ }^{8}$.

Assim, para além da questão humanitária, também por razões econômicas é mais vantajoso ofertar políticas sociais (prevenção, assistência e tratamento) para o enfrentamento desse problema global, pois mesmo em países com baixa incidência de casos é menos oneroso assumir um contrato social mais inclusivo "do que tratar as pessoas doentes ou assumir os efeitos da perda de capital humano e social"".

No passado, os efeitos da epidemia para os países em desenvolvimento eram considerados como equivalentes a eventos isolados deum processo econômico que as economias nacionais poderiam absorver, escapando do controle dos planejadores. Acreditava-se que a prevalência da epidemia em $10 \%$ da população de um país em desenvolvimento significaria $0,5 \%$ deredução no crescimento econômico/ano. Pensava-se, então, que o Produto Interno Bruto (PIB) per capita aumentaria se a diminuição do PIB fosse menor que a diminuição da população ${ }^{3}$.

Esse reconhecimento dos custos sociais e financeiros da epidemia a médio e longo prazo ea existência de modelos de resposta bem-sucedidos, como 0 aplicado no Brasil, têm auxiliado a discussão e a defesa da ampliação do acesso aos medicamentos ARV pelos sistemas de saúde nacionais.

Apesar da evidente relevância da análise dos custos sociais da aids para escolha de políticas mais adequadas, no processo decisório brasileiro, há al go mais a ser considerado. N o Brasil, este discurso podeter auxiliado, mas não foi determinante para o processo de tomada de decisão no qual as especificidades do momento sociopolítico e da mobilização social foram decisivas.

No país, os primeiros casos de aids surgem na classe social dotada de potencial vocalizador das suas demandas e no mesmo momento em que há uma intensa mobilização pela retomada da democracia e pela reconstrução de um sistema deproteção social maisinclusivo, queresultou na nova Carta Constitucional de 1988, que universaliza 0 acesso à saúde e à assistência social. Tal universalização, tardia se comparada ao mundo desenvolvido, adota iniciativas dos modelos de proteção social fundados nas bases do Welfare State. Para os brasileiros que viviam com HIV e/ ou aids, esta conquista foi primordial. O Sistema Ú nico deSaúde(SUS), jáintegrado ao texto constitucional, recebe amparo jurídico, imprimindo aos bens eaos serviços de saúde o caráter de direito inalienável de cidadania e configurando seu não acesso como uma ilegalidade 8 .

De acordo com o texto constitucional aprovado em 1988, o Sistema Ú nico de Saúde (SUS) brasileiro passa a ter quatro características principais. A primeira delas é a universalização da assistência, garantida a todo cidadão e não mais restrita aos trabalhadores com contrato formal de trabalho e contribuintes do sistema - e seus 
dependentes. A segunda é a descentralização da gestão com direção única nas esferasfederal (exercida pelo M inistério da Saúde), estadual (comandada pelas Secretarias Estaduais de Saúde) e municipal (exercida pelas Secretarias M unicipais deSaúde). A terceira éa integralidade da atenção ( efetivada por meio de todas as ações necessárias à promoção, prevenção cura e reabilitação). Final mente, a quarta característica é a participação da comunidade na gestão do sistema (por meio das Conferências e Conselhos de Saúde, também instituídos nas três esferas de governo).

Os princípios constitucionais do SUS são complementados pelas leis n' 8.080 e 8.142, aprovadas em 1990, quefixam os parâmetros de funcionamento do sistema, configurado por uma rede de serviços públicos e privados descentralizada, regionalizada e hierarquizada, onde o setor privado deve ter uma participação complementar, através de convênios e contratos firmados com a esfera pública, com prioridade de participação para as instituições filantrópicas esem fins lucrativos. A fonte definanciamento do SUS passa a ser o Orçamento da Seguridade Social, um dos três principais elementos do orçamento nacional. Esteorçamento financia, além da saúde, a Previdência e a Assistência Social.

A quarta característica do SUS (participação e controle social), a previsão constitucional da integralidade da atenção em saúdee a universalidade do acesso ao sistema são fundamentais para o fornecimento dos anti-retrovirais. Em decorrência da demanda e da pressão social, em 1991, começa o fornecimento de medicamentos para infecções oportunistas. Em 1994, é oferecida a terapia anti-retroviral, com a distribuição gratuita apenas da zidovudina (AZT) e da didanosina (DDI). A partir de 1996, após ampla divulgação na mídia mundial da existência de novas drogas, a terapia tripla passou a ser oferecida aos cidadãos brasileiros portadores de aids. A política brasileira demonstra que ações combinadas de prevenção, deassistência e detratamento com acesso aos medicamentos específicos apresentam uma relação custo-benefício vantajosa.

Em 2003, Teixeira, Vitória e Barcarolo estimaram que 160.000 pessoas usassem a terapia anti-retroviral (TARV) e para estes autores isto espel hava a cobertura"com al guma forma detratamento" de quase todas as pessoas que vivem com HIV/Aids (PVHA) no país?. Hoje, o número médio de PVHA em uso de TARV é de $171.409^{10}$. Entre 1996 e 2002, a política (combinada) implantada fez a velocidade de crescimen- to da epidemia diminuir ea incidência da doença caiu $46 \%$ de 1998 para 2002. Apesar do número de internações por aids no SU S não haver reduzido ao longo do tempo, o número de internações das PVHA em uso de TARV diminuiu. Em 1998, a taxa de hospital izações por aids por paciente em uso de terapia ARV, no Brasil, era de $63 \%$; em 2004, passou para $26 \%$.

Estas constatações têm, em conjunto, demonstrado a virtuosidade desta política assistencial [que] perdeu a tradicional denominação de gasto público para assumir a missão de investimento público, utilizando-se dos conhecimentos e dos recursos técnicos, epidemiológi cos, estatísticos e financeiros como justificativa ${ }^{8}$.

Quando o Brasil inicia a distribuição universal e gratuita do primeiro ARV, a zidovudina, o custo da manutenção da terapia em cada paciente é elevado porque o medicamento precisa ser importado. Para viabilizar a sustentabilidade financei ra do programa, o Estado incentiva a produção nacional do AZT por um laboratório privado ${ }^{11}$. Em seguida, ações combinadas de pressão para a redução dos preços, a ameaça constante de quebra das leis de proteção às patentes por meio da "licença compulsória" -, a produção local dos fármacos (com o princípio ativo importado) e, ainda, a instituição dos medicamentos genéricos no país, resultam na redução dos custos de fornecimento e no estabelecimento de melhores patamares de negociação com o complexo industrial farmacêutico ${ }^{11}$.

A política brasileira, além do aspecto financeiro, também possui aspectos logísticos e estratégicos que em um país com a dimensão do Brasil não podem ser minimizados. Vale destacar que o fato do país dispor de um Sistema Único deSaúde, de uma rede de serviços e profissionais treinados em diagnóstico, preven ção etratamento deHIV/aids foram elementos fundamentais para a implantação da distribuição de medicamentos anti-HIV.

Além dessa particularidade da conjuntura política nacional no Brasil, Cassier e Correa ${ }^{15}$ destacam três fatores centrais na experiência brasileira, que são: primeiro, o fato dos direitos de propriedade industrial no país permitirem, até 1996, a cópia legal das invenções; segundo, a pressão exercida pelo movimento social sobre o $\mathrm{M} \mathrm{i-}$ nistério da Saúde, que o levou a adotar a política de acesso universal aos anti-retrovirais; e por último, o fato desta experiência estar baseada num processo de aquisição de conhecimento sobre drogas copiadas. 
Assim, não é ao acaso que o Brasil se torna doador de tecnologia junto ao Fundo Global e tampouco é casual que, hoje, a maior parte dos países do mundo procure estratégias para se aproximar do que é oferecido (e do que se conquistou), por meio da parceria estabel ecida entre a sociedade e o Programa Nacional de Doenças Sexualmente Transmissíveis e Aids.

A política brasileira mais uma vez éreconhecida como acertada após o estudo multicêntrico finalizado, no primeiro semestre de 2004, pela Universidade do Estado de São Paulo (USP) sobre adesão e tratamento. N este estudo, é analisado o custo do tratamento de mais de 37 mil pacientesem unidades de saúde diferenciadas, em cinco grandes capitais brasileiras. Constata-se falha no tratamento em menos de 30\% dos casos. Em um país da extensão do Brasil, com uma diversidade cultural de mesma proporção, os baixos índices de escolaridade das pessoas que vivem com HIV/ aids, a dificuldade de ingerir por vezes mais de trinta comprimidos/dia, a necessidade de realizar exames com freqüência e todas as possíveis fal has na gestão e/ou na operacionalidade do SUS, isto pode ser considerado um sucesso.

Em 2000, o país contabiliza a prevalência de $0,6 \%$, contra uma estimativa do Banco Mundial de $1,2 \%{ }^{10}$. E em agosto de 2002, o Congresso Mundial de Aids de Barcelona ${ }^{11}$ fecha seu relatório final sobre os trabalhos submetidos ao congresso com dez chamadas para as idéias centrais debatidas, dentre as quais estava a informação a seguir: há dois anos atrás foi informado que um total de 158.168 pessoas haviam recebido ou estavam recebendo a terapia anti-retroviral nos países debaixo e médio desenvolvimento. D estas, $100 \mathrm{mil}$ pessoas são do Brasil, 506 pessoas vivem em outros países latino americanos; 13.533 pessoas na África e 12.121 pessoas na Ásia. A terapia profilática em mulheres grávidas foi disponibilizada para 7.324 mulheres na África, 558 na América Latina eape nas 140 na Ásia. A despeito do reconhecimento internacional (em 2003, o Programa Nacional de DST/aids brasileiro foi contemplado com o Prêmio Gates de Saúde Global) ${ }^{12}$ e dos resultados positivos do programa brasileiro, outras medidas podem ser implantadas nos países de médio ou baixo desenvolvimento, mas não o são devido à proteção do acordo TRIPS. Por exemplo, a combinação de diferentes drogas num mesmo medicamento significaria barateamento dos custos do tratamento, bem como facilitaria a adesão à terapia e garantiria maior qualidade de vida aos pacientes. Diferentes drogas pertencem a cor- porações distintas e estão protegidas por suas respectivas patentes. Além disto, o controle e multiplicidade de licenças de propriedade intelectual e de patentes inviabilizam a produção de medicamentos genéricos a preços mais acessíveis.

\section{Discussão}

Dourado et al. estudaram a evolução epidemiológica temporal da aids se utilizando das bases de dados do M inistério da Saúde de 1990 a $2003^{13}$. Estes autores concluíram que as mudanças observadas no perfil de morbi-mortalidade da epidemia deAids no Brasil poderiam ser explicadas pelo amplo acesso a terapia anti-retroviral ${ }^{14}$. Porém, "0 acesso universal a TARV, cujo impacto sobre a mortalidadeéinquestionável, não ésuficientepara explicar a desaceleração do crescimento da epidemia". Para enten der este processo, medidas ecampanhas de prevenção; implantação de novos centros de testagem e aconsel hamento e do teste rápido para diagnóstico sorológico do HIV; a disseminação do conhecimento da população sobre o HIV/Aids; o grau de escolaridade e outros fatores socioeconômicos devem ser observados ${ }^{15}$.

0 conflito entre direitos humanos e interesses do mercado, nesses vinte anos, nunca deixou de ser enfrentado. Em 4 de maio de 2007, 0 governo brasileiro decretou o licenciamento compulsório da patente do medicamento Efavirenz por meio do Decreto $n^{\circ} 6.108$, viabilizado pela Portaria n ${ }^{\circ} 886$ de 24 deabril do mesmo ano, que considerou o produto de interesse público.

Este anti-retroviral é o medicamento importado mais utilizado no tratamento da aids. Atualmente, 38\% dos doentesutilizam o remédio nos seus esquemas terapêuticos. Estima-se que, até 0 final de 2007, 75 mil das 170.409 pessoas que vivem com HIV/aids em tratamento com terapia anti-retroviral farão uso deste medicamento. 0 Efavirenz é fabricado pela indústria farmacêutica M erk Sharp \& D ohme, que não cedeu aos argumentos do Ministério da Saúde com vistas à redução do preço do produto. As negociações com a empresa transcorreram por mais de cinco meses, iniciando-se em novembro de $2006^{16}$.

0 decreto com o licenciamento compulsório viabiliza a compra, pelo M inistério da Saúde, de versões genéricas do Efavirenz em três laboratórios indianos pré-qualificados pela O rganização Mundial da Saúde(OM S). Esta decisão foi apoiada por instituições e organizações governamentais enão governamentais nacionais einternacio- 
nais, tais como a Associação Brasileira Interdisciplinar deAids (Abia), Grupo PelaVidda, Sociedade Brasileira para o Progresso da Ciência (SBPC), UNICEF, M édicos sem Fronteiras e a Fundação Bill Clinton.

A queixa americana apresentada contra 0 Brasil na OM C, ainda em 2001, é apenas a ponta do imenso iceberg que revela a significativa desigualdade existente entre os povos e a multiplicidade de questões que orbitam em torno da estratégica questão do acesso a medicamentos. 0 conflito entre direitos humanos e interesses do mercado está expresso também na não implantação efetiva do "Acordo de Doha", importante conquista diplomática e comercial obtida pelos países em desenvolvimento durante a IV Conferência M inisterial da OM C, realizada em 2001 em D oha, no Q atar. Este acordo estabelece que o TRIPS não deve se sobrepor às questões de saúde pública, ou seja, a função social da produção demedicamentos e equipamentos deveestar acima dos interesses comerciais. Essa declaração é um forte instrumento de inclusão social, pois busca garantir o acesso a medicamentos como uma responsabilidade universal e um compromisso com a solidariedade e os direitos humanos. Seu cumprimento ampliaria o acesso aos medicamentos para milhões de portadores de doenças como hanseníase, tuberculose, diabetes, câncer, Alzheimer, mal de Parkinson ou hepatite. Entretanto, devido às resistências interpostas pel os países que hoje são detentores de patentes, a lógica solidária da declaração não consegue sair do papel desde 2001.

Tanto os detentores de capacidade interna de produção quanto os desprovidos dela poderiam, de acordo com a declaração, importar gené ricos, se isto elevar o acesso aos medicamentos, sejam os comprados nas farmácias ou os distribuídos gratuitamente pelos programas públicos de saúde. Países como o Brasil, que têm estrutura produtiva, poderiam também exportar esses genéricos para atender às necessidades de outras populações. Além disso, a declaração de Doha cria mecanismos de negociação com os laboratórios detentores de patentes, legitima a concessão de licenças compulsórias de patentes a labo- ratórios locais e abre espaço para outras medidas que garantam 0 acesso da população à saúdee a medicamentos.

Os países detentores de patentes exigem que se pactue uma lista mínima de doenças a serem contempladas no âmbito da declaração, iniciativa rejeitada pela OMS e pelos países pobres, que exigem o direito de aplicar o disposto em $D$ oha de acordo com as necessidades de cada nação. Para assegurar seu direito às patentes, os Estados U nidos, por exemplo, estão inserindo mecanismos reguladores na linha inversa ao aprovado em Dohanosacordos bilateraisquetêm firmado com cada Estado separadamente ${ }^{17}$.

A experiência brasileira mostra que a existência de um conjunto de fatores (mobilização social, legislação, financiamento público, descentralização do sistema de assistência à saúdecom centralização da decisão e o cálculo da economia de recursos com a implantação de políticas de prevenção etratamento) cria as condições necessárias à garantia de acesso aos medicamentos antiaids, promovendo um fortalecimento do Estado frente a outros grupos de interesse. Com base neste exemplo, pode-se concluir que outros países também podem construir um grau de autonomia interna que permita enfrentar a assimetria existenteneste campo.

Considerando a pertinência do debate estabelecido no campo das relações internacionais, cresceem importância o papel das $\mathrm{N}$ ações U nidas e de suas agências. N este sentido, se resta a este sistema e a seus órgãos algum papel, este não pode ser o de setransformar em mais um instrumento de sustentação do statusquo que caracteriza a atual assimetria nas relações interestatais. Pelo contrário, o que está colocado para este sistema é a construção de acordos e pactos que superem a assimetria e fortaleçam as sociedades que hoje buscam saídas para a crítica realidade em que se encontram. Caso não assuma este papel ereconstrua a sua atuação de forma a responder aos desafios hoje colocados, a Organização das N ações Unidas corre o risco de se enfraquecer e perder sua importância histórica, justamentenuma conjuntura onde sua atuação firme e propositiva é essencial ao futuro do homem. 


\section{Colaboradores}

MH Costa-Couto trabalhou na concepção, levantamento de dados sobre a epidemia de aids no Brasil e no mundo; e na redação final. $A C$ $\mathrm{N}$ ascimento trabalhou no levantamento dos mecanismos reveladores da assimetria nas relações internacionais, dados referentes aos sistemas de propriedadeindustrial ena redação final.

\section{Referências}

1. Arrigui G. O longo século XX. Rio de Janeiro: Contraponto; São Paulo: Editora UNESP, 1996.

2. Fiori JL. Globalização H egemonia e Império. In: Poder e Dinheiro: uma economia política da globalização. Petrópolis: Vozes; 1997. p. 87-147.

3. Organização Mundial de Saúde (OMS). Informe sobre la salud en el mundo 2004 - cambiemos el rumbo de la historia. Genebra: OM S; 2004.

4. M édicos sem Fronteiras (M SF). Patentes de medicamentos em evidência. Rio de Janeiro: M SF; 2003.

5. Sutton M. Os medicamentos genéricos no contexto das políticas de acesso a medicamentos e regulação de preços no Brasil [tese]. Rio de Janeiro (RJ): Universidade do Estado do Rio de Janeiro; 2004.

6. Lei de Patentes. Como o Brasil foi vencido. Revista Atenção 1996; 2(4).

7. Pignarre P. A indústria farmacêutica mundial. Quebec: Universidade de Quebec; 2003.

8. Costa-Couto MH. Novos horizontes para as políticas públicas em HIV/AIDS: uma aproximação às questões da contemporaneidade [dissertação]. Rio de Janeiro (RJ): Universidade do Estado do Rio de Janeiro; 2003.

9. Teixeira P, Vitória M, Barcarolo J. The Brazilian experience in proving universal access to antiretroviral therapy. In: Economics of AIDS and Access to HIV/AIDS Care in Developing Countries, Issues and Challenges. Paris: ANRS, 2003.

10. M onitoraids - Sistema de M onitoração de Indicadores do Programa Nacional de DST/Aids. Disponível em: http://www.aids.gov.br

11. The Status and Trends of The HIV/AIDS Epidemics In the World. Barcelona Map Symposium. [site da Internet ] 2002 Jul 2-4. Disponível em: http://www. mapnetwork.org/barcpictures.shtml

12. Unesco. [site da Internet]. Disponível em: http:// www.unesco.org.br/areas/educacao/educacaosaude/ educacao_preventiva/projetos/billgates/index_html/ mostra_documento

13. Programa Brasileiro de DST e Aids. [site da Internet]. Disponível em: http://www.aids.gov.br

14. Dourado I, Veras M ASM, Barreira D, Brito AM. Tendências da epidemia de Aids no Brasil após a terapia anti-retroviral. Rev. Saúde Pública 2006, 40:9-17.

15. Cassier M, Correa M. Patents, innovation and public health: Brazilian public-sector laboratories' experience. In: ANRS. Copying AIDS Drugs. Paris: ANRS; 2003.

16. Nota de Esclarecimento. Disponível em http://www. aids.gov.br//data/Pages/LU M ISE77B47C 8ITEM ID 7 CAB7CAED C4C4B8A9FB773C2AC8C5EF1PTBRIE. $\mathrm{htm}$

17. M édicos Sem Fronteiras. [site da Internet]. Disponível em: http://www.msf.org.br/noticia/msfN oticias Mostrar.asp?id $=93$

Artigo apresentado em 19/07/2006

A provado em 16/05/2007

Versão final apresentada em 11/07/2007 